\title{
Adapting an English language textbook to the principles and laws of Suggestopedia
}

\author{
Dessislava Georgieva Todorova-Hlavacik*
}

\begin{abstract}
The article aims to describe the application of Suggestology in the pedagogical practice - Suggestopedia/Reservopedia. An overview of "suggestion" as a communicative factor and as a psychological basis for the science of Suggestology is presente together with the main principles, means and laws of Suggestopedia. Some characteristics of the suggestopedic textbook and my work in remodelling the original textbook "Energy for Bulgaria, for the 6-th grade" into a new stopedically adapted version are presented.
\end{abstract}

Key words: suggestion, suggestology, suggestopedia, suggestopedic textbook

\section{Introduction}

Teachers of foreign languages often have an idea about the teaching/learning process formed on their experience of studying foreign languages themselves. When teachers are informed and exposed to varieties of different methods they become more aware of their personal values and beliefs about the educational process. By being clear on their own assumptions teachers may choose to teach differently. Thus, the knowledge of various alternative methods will help them in modifying their current practices.

One humane method which deserves attention because it has proven to be effective for teaching many subjects including foreign languages is the method called Suggestopedia. It is based on the Suggestology science, and its founder is the Bulgarian scientist, psychotherapist and psychiatrist - Prof. Dr. Georgi Lozanov M.D., who in the 1950s began his search for safe ways to uncover the reserves of the human brain (mind) through suggestion and thus created the science of Suggestology. Doctor Lozanov was the director of the Research Institute of Suggestology founded by the Ministry of Education and the Bulgarian Science Academy in 1966, for the period of 20 years (1966-1985). He founded and directed the Center of Suggestology and Personal Development at the University of Sofia, an International Center of Desuggestology in Vienna and the International Center for training and specialization of teachers in Viktorsberg, Vorarlberg, Austria (Lozanov 2005b: 129-131), (Lozanov 2009: 216-219). In 1978 UNESCO international committee of twenty experts conducted a research on the Suggestology method, evaluated it as a higher form of education for different subjects and ages.

\footnotetext{
* BA student in the Department of English Studies, University of Shumen, Shumen, Bulgaria
} 


\section{The Nature of Suggestion and Suggestology}

Suggestion is a psychological term for the purposeful psychic influence on individuals or a group, perceived passively, without resistance or critical valuation. In other words it is based on trust. The part 'suggesto-' derives from the word 'suggestion' which in the field of Psychology means - the influencing of a person to accept a belief or an impulse uncritically. The word has Latin origin from the verb 'suggero', 'suggessi', 'suggestum' - put or lay under, prompt, suggest (Lozanov 1963: 47). In English it means "to propose, to recommend, to advocate, to advise, to evoke". This meaning of the word is used in Suggestopedia/Reservopedia. Thus, it is up to the participant's free will to accept or reject suggestion. "This refers, not only to what, but to how to propose, so that, for the person, the suggestion will be a most acceptable and natural thing and the anticipated phenomenon will occur." (Lozanov 2009: 29).

\section{Suggestopedia: Definition, Principles, Means and Laws}

Suggestopedia develops as "a tendency in pedagogy and simultaneously as an experimental method of suggestology" (Lozanov 1971: 7). In 1966, along with the founding of the Institute of Suggestology, Dr. Lozanov announced for the first time the category suggestopedia in the article "Suggestology - a way to the hypermnesia in the educational process. The method of the Suggestopedy", published in Narodna Prosveta magazine (Lozanov 1966: 23-41). A year later during the International Week of Psychosomatic Medicine in Rome, doctor Lozanov used the same term in English - suggestopedia (Lozanov 1967: 535539), (Lozanov 2005a: 11).

Suggestopedia (Suggestopedy, Suggestopaedia) is the process of educating and instructing in accordance with principles of Suggestology - the science of suggestion. Lozanov refers to his method not as an alternative to other methods but as a new culture, a new way of teaching and learning where "instead of automatic subordination to limiting norms about the capacity of the brain/ mind, there is a free yet at the same time organized and purposeful learning and personality development by means of spontaneous absorption of knowledge" (Lozanov 2009: 134). In his system the negative effects of the learning process are replaced by their opposites with a positive notion. Instead of fatigue and illness due to overload, there is rest and improved health. Instead of alienation, openness and socialization occurs. Instead of demotivation and lack of interest, there is high motivation and involvement in the learning process.

With the evolution of the method, Lozanov introduced the terms Desuggestology, Desuggestopedia, Reservology, and Reservopedia. He stressed that this does not mean the rejection of the terms Suggestology and Suggestipedia. The prefix "de-", at the beginning of Desuggestology and Desuggestopedia refers to "deprograming, de-suggesting" from the effects of the negative conditions of the 
environment. It relates to the "freedom of personality, the inner freedom" (Lozanov 2009: 14). With the acquisition of these terms Suggestopedia becomes a desuggestive pedagogy of the hidden reserves of the mind.

The theory of Suggestopedia/Reservopedia is based on the understanding that the learner is a whole personality. The globally integrative character of the methodology takes into account all of the brain functions involved in the learning process. The teaching suggestopedic theory construction emphasizes the psychological, neuro-physiological, artistic, pedagogic and psychotherapeutic aspects directed at utilizing the potential capacities of the brain.

Lozanov states that the three fundamental principles of his method are: "1./ Joy, absence of tension and concentrative psycho-relaxation; 2./ Unity of the conscious and integral brain activation; 3./ Suggestive relationship on the level of the reserve complex.'(Lozanov 1978b: 31).

Along with the defined principles of desuggestive-suggestive pedagogy, precise groups of means are established for the application of the method for various subjects, different age groups, etc. These groups of means consist of psychological, didactic, and artistic means (in the sense of the means of art).

Lozanov formulates precisely the obligatory conditions in the suggestopedic education which he calls the seven laws of the Reservopedic teaching system. They intertwine closely and must be respected in all stages of teaching process.

\section{- The First Law of Suggestopedia/Reservopedia: Love}

It is well known that nothing great in this world has been accomplished without love. An essential condition for accessing the reserves of the mind is also love. It creates serenity, trust and contributes to the prestige of the teacher in the eyes of the students and thus taps the paraconscious personality's reserves. Love cannot be played or faked. Lozanov explains that "it should not be understood as some sentimental, soft mood, since this attitude brings about negative reactions. Love should be experienced as genuine love for the human being " (Lozanov 2009: 56).

\section{- The Second Law of Suggestopedia/ Reservopedia: Freedom}

In the core of the law of Love is Freedom. It makes Reservopedia so distinct from the hypnotic method. It enables the teacher to make personal decisions within the main reservopedic framework of the lesson to adapt it to the needs of each group. Students can choose whether to take part in some activities such as a game, a song, etc. that might not harmonize with their disposition at the moment. They are allowed to go out of the classroom without disturbing the work of the group as a whole. This freedom is spontaneously created and not imposed by the teacher. 
- The Third Law of Suggestopedia/ Reservopedia: Teacher's Conviction that Something Unusual is Taking Place

This law concerns the teacher's conviction that something unusual is taking place. This state of inspiration is reflected in the teacher's verbal and non- verbal communication and in the peripheral perceptions and then it spontaneously resonates in the students without hesitation. Through the teacher's positive message, their genuine signals of expectation and support the students get the feeling that they achieve easily everything on their own. In such way "the so called suggestive relationship is created at the level of the reserve complex." (ibid.: 58).

\section{- The Forth Law of Suggestopedia/ Reservopedia: Manifold Increase of Input Volume}

The study material presented to students, for a certain period, must have at least two to three times greater volume than the established norm by other methodologies. Along with that the material should be absorbed five to ten times faster without strain and with positive effect on health. For example, a one month foreign language course consists of 2000-2500 lexical units.

\section{- The Fifth Law of Suggestopedia/ Reservopedia: Global- Partial, Partial-Global, Partial through Global}

With the suggestopedic method, in all subjects, the new study material must be given in its total wholeness and without separation of the elements from it. They are never to be taught and learned in isolation. This law is based on brain-functioning research, which suggests that the componential parts of the brain contain information about the whole brain. Furthermore, the human being reacts as a whole, in a complex way, to the environmental stimuli.

\section{- The Sixth Law of Suggestopedia/ Reservopedia: The Golden Proportion}

The golden proportion as a principle is considered the most perfect proportion in the universe and is also known as the golden mean or the golden section. Euclid wrote about it for a first time in the third century B.C. Many philosophers, scientists and architects have been interested in it ever since. In Suggestopedia, the golden proportion is a substantial concept and is intentionally used throughout the educational process. Because of that, fatigue is prevented and suitable conditions for learning large amount of material in a short span of time are created.

- The Seventh Law of Suggestopedia/ Reservopedia: Use of Classical Art and Aesthetics

In Reservopedia classical art and aesthetics are essential, viewed as the main suggestion mediator in the non-manipulative communication and a transmitter 
of an indefinite number of non-specific stimuli which nourish the abundance of peripheral perceptions unnoticeable to the conscious awareness. Gateva states that: "multi-leveled information offered by the artistic work is absorbed in multitunneled way, and then re-structured, recorded, and re-associated in a multileveled way" (Gateva 1991: 24). Classical art affects both mind and emotion and is introduced through especially selected works of classical music, songs and arias, literary selections, reproductions of masterpieces, etc.

\section{Restructuring and Adaptation of Energy for Bulgaria, Students' Book for the 6-th grade to the Suggestopedic Method}

Of a major importance to the success of the suggestopedic process of teaching and learning is the textbook. A pleasant story with a light emotional plot is presented in accordance with the suggestopedic principles and organized to use effectively the psychological, pedagogical and artistic means. According to Gateva:

The particular method of the textbook is a story within the story. ..., one might think this would hinder the absorption and retention of the educational content - but it is not so. The genre variations, the changes and the paradoxes which help students master the educational information are put forward at the first frequency. The repeating models with new variations in successive lessons immediately introduce a feeling of ease. ..., students are immersed in the natural surroundings of the country throughout the story (Gateva 1991: 222).

As a part of an experiment approved by "Prof. Dr. Georgi Lozanov and Prof. Dr. Evelina Gateva" Foundation, I had a chance to restructure and adapt the Energy for Bulgaria, Students' Book for the 6-th grade (Elsworth, Rose 2007), to the suggestopedic requirments and standards. The innitial aim was to help a student who had a psychological trauma of learning the English language at school and the perspective was that if satisfactory results are achieved the textbook can be used with other students in the same age group.

I proceeded by reading the original text as a whole in order to identify the protagonists and find a plot to develop a story based on it. Then I defined the global themes around which I can organise the given matherial. Thus, the three chapters of the suggestopedic textbook were structured by combining three to four units of the original. In accordance with the theoretical development of suggestopedic teachings and maintaining the artistic and global approaches I used as a model for my work of The Return, An English Suggestopedical Textbook (Gateva, Lozanov, König 1991), the descriptions given in Suggestopedic Practical Guidance for Teachers of Foreign Languages (Lozanov, Gateva 1981), The Foreign Language Teacher's Suggestopedic Manual (Lozanov, Gateva 1988) and the first chapter of the suggestopedic textbook for the 5-th grade made by Vanina Bodurova from "Prof. Dr. Georgi Lozanov and Prof. Dr. Evelina Gateva" Foundation. 
The main purpose of the textbook was to increase the students' interest and motivation in studying the English language, so that they are able to communicate easily and quickly. The story involves characters and situations connected with the contemporary students" life in the "Limelight Theatre School" in London, and combines realistic events in which the five main characters are involved. Each character has specific psychological and physical characteristics (Vasi, a school exchange student from Bulgaria; Storm, from London, a red-haired classmate and guide of Vasi; Mickey, a singing and dancing football player from Manchester, who goes to the same theater school; Mo, a boy from Cape Town, South Africa, who plays drums and trumpet; Jess, from Colorado, USA, she acts and sings and can even drive a truck). The other characters appear or re-appear partially. The characters are played by different children during the elaboration stage of the suggestopedic process but the roles are never fixed. The stressful and shocking moments are removed from the original text "since they provoke extreme agitation and are psychologically burdensome." (Gateva 1991: 191).

The first chapter of the suggestopedic text book with the title Realm of Magic is "First Days in London" and consists of the introductory topic of the original textbook - "First Day in London", Unit 1 - "School life", Unit 2 - "Free time" and Unit 3 - "Food". The chapter starts with a few lines from the song "What a Wonderful World"(by G. D. Weiss and B. Thiele), just below the title and gives the basic idea of the chapter. The lyrics of the song are also included later in the text. That "creates a particular rhythm in the work, and an emotional-logical state of anticipation which aids the effectiveness of the teaching" (Gateva 1991: 192). The text is presented in a form of dialogue with the English lines on the left side of the pages and the Bulgarian translation symmetrically given to the right forming two language columns. The sentences are broken down to groups of words or separate parts of speech, so that they can be replaced with other word forms or parts of speech while elaborating the text later in the process. The story begins with Vasi's arrival at the "Limelight Theater School" in London and her first meeting with Storm. The language is both formal and informal. The new lexical units are in bold letters in both languages as well as the new grammar categories and paradigms are given on the right side of the pages with the translation. They follow after the particular use of some of the grammatical forms in the text. During the elaboration stage the translation can be covered depending on the mastery of the new material by the students. The meaning of the text is indirectly supported by reproductions, photographs, illustrations, pictures and drawings, such as Miss Eden by John Singer Sargent, London - Fog Over Thames by Leonid Afremov, Dance Finesse by Richard Young, London Phone Booth by Pablo Solares, Valentine's Day by Pat Fiorello and others. They stimulate the scientific-artistic thinking of the students and help the language acqusition. The teddy bear cartoon characters from the Forever Friends edition, smiling emoticons and funny pizza faces are used as well. At the end of the 
chapter the thematic lexical units and grammar used in the text are given on the left side of the page just as terms with no additional descriptions, explanations or translations but the teacher must develop them artistically and with games.

The second chapter or part two of the suggestopedic text book is "My Country" and combines Unit 4 - "My country", Unit 5 - "Holidays" and Unit 6 - "The Earth in danger" from the original textbook. The chapter begins with a stanza from the poem "Auguries of Innocence" by William Blake (Blake 1994: 127) and continues with the dialogue of some of the main characters in the story. The structure of the English text and the translation are the same as in the previous chapter and the perception of the text is stimulated by reproductions, pictures and drawings. The photography of an ice hotel in Jukkasjärve in Sweden is used. The lyrics of the song from the Disney movie Pocahontas - "The Color of the Wind" are included in this chapter which finishes again with the thematic lexisical units and grammar used in the text.

Following the above-described pattern the third part of the suggestopedic textbook contains the compiled version of the original Unit 7 - "The Invisible Man", Unit 8 - "Feelings and emotions", Unit 9 - "Relationships" and Unit 10 - "Film and TV", and is entitled "The World of Imagination". It begins with the lines from John Keats' poem "Endymior" (Keats 1956: 42), but here in contrast to the previous two chapters the translation is not given. It provokes the students to make the translation themselves on the following day after the concert session, which begins the elaboration on stage of this theme in the suggestopedic process. In addition it is also a good way to stimulate discussion based on the poem's content. The translation for the rest of the text is given. In this chapter the visual aids are again drawings, pictures and paintings. In this chapter the song included in the text is "Don't Worry, Be Happy" by Bobby McFerrin. The chapter finishes with Khalil Gibran's words quoted from Mary Haskell's journal dated $7^{\text {th }}$ June 1912. At the end of the text the thematic lexical and grammar are given.

The main difference between the Energy for Bulgaria students' book for the 6-th grade and the suggestopedic textbook with the working title Realm of Magic is in the texts layout and the structural parts. The Energy for Bulgaria provides and develops previously thought grammar and vocabulary and integrates the development of reading, listening, speaking and writing skills through exercises. The reading and listening skills are improved by dialogues and texts corresponding to the psychological and social characteristics of the students in the 6-th grade and are from different fields of life. This gives ground for discussions which develop the speaking skills. The listening and reading skills are activated also with multiple choice exercises, true or false exercises which can be done in written form as well. Speaking - the active usage of the target language is an important part in the foreign language education. The exercises stimulating this skill are: making dialogues using preliminary plans or prompts, 
asking and answering questions on a specific topic, speaking about oneself or somebody else, telling a story using pictures or talking about different places, people or events. Similar exercises can again be done in written form.

Each Unit in the original textbook is divided into Focus sections numbered one to six and additional part Energy Check finalizes the Unit. An example of this structure in the first unit follows: Unit 1 - School Life; Topics: The World around $\mathrm{Me}$ - School life; Grammar: Present simple; Negative questions; too/enough; as...as; Prepositions: for; Vocabulary: School subjects; Communication: Show surprise; Apologize. Focus 1 of the unit is "Switch on" and consists of reading, grammar, pronunciation, communication and roleplay parts. Focus 2 is "Grammar - Present simple" and starts with a table of positive, negative, questions, short answers, Wh-questions and time markers specific for the present simple tense. The same focus continues with four writing and speaking exercises. Focus 3 is "Vocabulary - School subjects" and aims at the speaking skills activated by six exercises. On the next page Focus 4 deals with "Grammar - too/enough, as...as" in five reading and writing exercises. Focus 5 is "Communication - Is your bag too heavy?" and is mainly concerned with the development of the speaking skills. Focus 6 is "Skills - School for starts" and contains seven reading, listening and speaking exercises. The unit finishes with the "Energy Check" and consists of eight written exercises and additional short texts on the next page under the title "Cultural Bite - School's out". In each of the Focus sections there are Memory Tips, Grammar Spot and Remember Rectangles which are highlighted by different colors. Also there are sections Memory Gym and Writing Gym. Following the same model all the other units are formed with some slight differences in the number of focuses in each unit, which can be five or six as well as the main activities aimed on different skills.

The suggestopedic textbook, as described above has only three chapters containing the same study material as from the course book approved by the Ministry of Science and Education in Bulgaria. The description of each of the chapters was mentioned earlier and is in unison with the suggestopedic principles, means and laws. It is obvious that the text resembles a scenario. The new vocabulary and grammar are integrated into the text but bolded to stand in contrast with the rest of the text. Another significant difference apart from the layout and the given translation is that in the suggestopedic textbook there are no exercises. This does not mean that the activation of all of the skills in learning and using a foreign language are not stimulated and practiced. The newly acquired knowledge is mastered by the students in the elaboration stages where many games based on didactic material are used as well as some of the didactic songs written by Gateva for the English language courses for adults and used with the suggestopedic textbook The Return. It should be pointed out that the suggestopedic classroom, center or studio is decorated with reproductions of different art masterpieces and also with didactic charts and posters containing the grammar categories and materials. 
The textbooks Energy for Bulgaria students' book for the 6-th grade and the suggestopedic variant Realm of Magic are designed for usage with different methodological approaches. There is not a teacher's book for the suggestopedic variant and the suggestpedagogue should develop the games and exercises in accordance to the study material to his/her personal preferences having in mind the individual characteristics of the students in the group or adapt materials already used with other suggestopedic textbooks. This creative process is very stimulating and rewarding for the teacher and serves entirely the suggestopedic law of freedom. I am convinced that the textbook is fundamental in the process of learning a foreign language. The comparison and evaluation based on the description of the two textbooks is not suitable and is unnecessary because the teachers who use them are trained to work with the specific educational system and the tools provided by it. My personal opinion is that the suggestopedic method and hence textbook makes the learning process more interesting, enjoyable and thus by providing opportunity for self-expression high motivation leading to high results are achieved.

I had to add another chapter to the text because the material in the textbook was well mastered and exercised by the end of the Easter Holiday. I had the permission to use a material which was developed for the 5-th graders by Vanina Bodurova from "Prof. Dr. Georgi Lozanov and Prof. Dr. Ivelina Gateva" Foundation. In it I only adapted the names of the characters in order to continue the story. When this chapter was mastered and repeated I used some extra texts taken from More Tell Me Why (Leokum 1973: 313-319): "How Did Music Begin?”; "Why Do We Dance?"; "Who Wrote the First Opera?" etc.

Before the summer holiday I had enough time to develop another material based on the musical The Sound of Music. I used video and audio short interviews, recordings, award ceremonies, historical date both about the real characters whose story was retold in the musical and the leading actors. It gave me a chance to include materials about Austria, Salzburg and the Alps. The songs from the musical were sung with great pleasure and the lyrics were involuntary memorized. No printed material (except for the lyrics of the songs) was given and both speaking and listening skills were well trained.

Because the experiment with the suggestopedic textbook proved to be successful based on the tests in oral and written forms, as well as because a positive change in the foreign language perception of the student was witnessed, the Realm of Magic was used in the English suggestopedic classes with 6-th graders in the academic year of 2015/2016 in "Liuben Karavelov" secondary school in Koprvivshtitza. The teacher was Neshka Kuncheva who is a suggestpedagogue trained by Vanina Bodurova, "Prof. Dr. Georgi Lozanov and Prof. Dr. Evelyna Gateva" Foundation. Kuncheva shared that in total during the first academic term she had five hours per week and during the second term they were six hours per week. The hours were merged in a block of $90 \mathrm{~min}$ with a $10 \mathrm{~min}$ 
break which was ommited when there were concert sessions. But this did not bother the students, she wrote, and they did not even hear the school bell or the other students who were having break at that time because they were highly interested in the text. Each global theme she elaborated for approximatly two months because she was trying to keep pace with the distributional norm for the material given by the Ministry of Education. The globalized themes were developed, elaborated and repeated faster by the students than the academic plan required. The teacher had to add more games, exercises, songs in order to prolong the process and in order for the grammar and lexical units to be mastered well. The results at the end of the academic year were better in comparison to the previous year. The number of students in the class was twelve. At the end of the year the students having excellent marks were seven compared to four in the year before. All other students had marks one point higher, and the lowest mark was four (good).

Not only was my personal experience with the textbook positive, but Kuncheva shared her approval and satisfaction as well. This observation of the work with the textbook Realm of Magic is far from having scientific claims but shows that the suggestopedic method can be applied successfully with sufficient results and with positive effect on the students in class if it is used by a trained suggestopedagogue and study materials developed in accordance with the means, principles and laws of Suggestopedia.

\section{Conclusion}

From my teaching experience with the suggestopedic method for the last four years I can personally report and prove the high results achieved in the learning process. One should not be an expert to be able to compare and clearly see the difference between the entrance (pre-tests) and final tests (post-tests) of the students. But nothing can compare with students' joy and the positive effect on their personality as a whole expressed in their increased interest in science, art and in the awakening of their creativity. The process is truly charging, healing, renewing, awakening the desire for knowledge and expression of oneself. It brings happiness to the students and to the teacher as well.

Teachers should encourage the development of students' potential and motivate them to re-discover the joy in learning. To be able to achieve this they should create a stress-free and non-threatening learning environment for their students. In order to do that the teacher should be aware of the scientific research findings in the field of brain/mind functioning. The teachers' role is of major importance, as on their knowledge and mastery not only of the classroom management, but the success of the students is largely dependent. Suggestopedia can be the tool which makes a difference in that case. But it is not to be seen as a "magical" method unless it is harmonized with the skills, abilities, dedication and love of the teacher using it. 
A highly motivated teacher, aware of the significance of his/her own motivation and the effect s/he produces on the students, is constantly learning in order to be able to use all of his/her knowledge in the classroom activities and organization. This will diminish the "burnout" effect and will not keep the teachers in a stagnate state of repetition and use of old materials, programs, etc.

\section{References:}

Blake 1994. Blake W. “Auguries of Innocence”. The Works of William Blake. Hertfordshire: Wordsworth Editions Limited, 1994.

Elsworth, Rose 2007. Elsworth S., J. Rose. Energy for Bulgaria, Students' Book for the 6-th grade. Harlow: Pearson Education Limited,2007.

Gateva 1991. Gateva E. Creating Wholeness through Art. United Kingdom, Aylesbury: Accelerated Learning Systems Ltd., 1991.

Gateva, Lozanov, König 1991. Gateva E., Lozanov E., M. König. The Return, An English Suggestopedical Textbook, Sofia: St. Kliment Ohridski University Press, 1991.

Keats 1956. Keats J. Keats- Poetry and Prose. Oxford: Claredon Press, 1956.

Leokum 1973. Leokum A. More Tell Me Why. London: Odhams Books, 1973.

Lozanov 1963. Lozanov G. "Vnushenieto". In Sharankov Em., Lozanov G., Petrov I., A. Atanasov. Rykovodstvo po psihoterapiya. Sofia: Meditsina i fizkultura, 1963.

Lozanov 1966. Lozanov G. "Sugestologiyata - pyt kym hipermneziya w uchebniya protses. Metodika na sugestopediyata". In Narodna prosveta, book 6. Sofia, 1966.

Lozanov 1967. Lozanov G. Suggestopedia and Memory, Proceedings of the International Psychosomatic Week, Rome, 1967.

Lozanov 1971. Lozanov G. Sugestologiya. Sofia: Nauka i izkustvo, 1971.

Lozanov 1978a. Lozanov G. Suggestology and Outlines of Suggestopedia, New York: Gordon and Breach, 1978a.

Lozanov 1978b. Lozanov G. Suggestology and Suggestopedia-Theory and Practice, Sofia: Working Document for the Expert Working Group, $1978 \mathrm{~b}$.

Lozanov 2005a. Lozanov G. Sugestopediya - desugestivno obuchenie. Komunikativen metod na skritite v nas rezervi. Sofia: Universitetsko izdanie Sv. Kliment Ohridki, 2005a.

Lozanov 2005b. Lozanov G. Suggestopedia - Desugestive Teaching. Communicative Method on the Level of the Hidden Reserves of the Hunam Mind. Vienna: International Centre for Desuggestology, $2005 \mathrm{~b}$.

Lozanov 2009. Lozanov G. Suggestopedia/Reservopedia. Theory and practice of the liberating-stimulating pedagogy on the level of the hidden reserves of the human mind. Sofia: St.Kliment Ohridski University Press, 2009.

Lozanov, Gateva 1981. Lozanov G., E. Gateva. Sugestopedichno praktichesko rakovodstvo za prepodavateli po chuzhdi ezitsi. Sofia: Nauchnoizsledovatelski institut po sugestologiya, 1981.

Lozanov, Gateva 1988. Lozanov G., E. Gateva. The Foreign Language Teacher's Suggestopedic Manual. New York: Gordan and Breach Science Publishers, 1988. 